\title{
SIMULATION AND ROBUST CONTROL OF CONTINUOUS TIME CIRCULATING REACTOR
}

\author{
Zdenka Prokopová and Zuzana Oplatková \\ Department of Applied Informatics \\ Tomas Bata University in Zlín, \\ Nad Stráněmi 4511, 76005 Zlín, Czech Republic \\ E-mail: prokopova@fai.utb.cz
}

\section{KEYWORDS}

Modelling, Simulation, Circulating reactor, Algebraic approach, Robust control, Uncertainty.

\begin{abstract}
The aim of presented paper is analysis, mathematical modelling, simulation and control of hydrogenation process. Cyclohexane, as an important base material for polyamide manufacturing, makes by catalytic hydrogenation of benzene. A large number of reaction heat transfers during hydrogenation process. Therefore, benzene and cyclohexane mixture hydrogenation proceed under hydrogen excess. We suppose the hydrogenation mechanism of benzene as a first-order reaction. Matlab-Simulink toolbox was used for robust control simulation with application to the circulating reactor. Robust controllers are obtained via solutions of Diophantine equations in the ring of stable and proper rational functions. Uncertainty and robustness are studied through the infinity norm $\mathrm{H}_{\infty}$. For controller design was proposed a scalar parameter $\mathrm{m}>0$ as a tuning knob.
\end{abstract}

\section{INTRODUCTION}

The behavior of real chemical process is obviously too complex for complete mathematical analysis. We are obliged to use an approximate description which is able to deliver sufficiently accurate results. Cardinal simplifications of the mathematical description can be obtained by the following supposals:

- the process does not change its properties during the observation period,

- the relation between input and output variables of the process is linear,

- all process variables can be measured continuously and have a continuous-time trend.

A useful and interesting application of reactor design for chemical engineers can be seen in (Froment and Bischotf 1990), (King and Winterbottom 1998). The treatment of biochemical and polymer reaction engineering is described very extensively in (Nauman 2002). There are emphases on numerical solutions which are needed for most practical problems in chemical reactor design. Sophisticated numerical techniques are rarely necessary. The aim is to make the techniques understandable and easily accessible and allow continued focus on the chemistry and physics of the process.

Robust controllers and plant uncertainty became a useful and popular discipline in control theory during the last decade. The necessity of robust control was naturally developed by the situation when the nominal plant (used in control design) differs from the real (perturbed) one. A suitable tool for parameter uncertainty is the infinity norm $H_{\infty}$. Hence, a polynomial description of transfer functions had to be replaced by another one. A convenient description adopted from (Vidyasagar 1995), (Kučera 1993), (Doyle et al 1992) is a factorization approach where transfer functions are expressed as a ratio of two Hurwitz stable and proper rational functions $\left(R_{s}\right)$. Then conditions of robust stability can be easily formulated in algebraic parlance and all controllers are obtained via linear Diophantine equations in an appropriate ring.

\section{MODEL DESCRIPTION}

Benzene and cyclohexane mixture hydrogenation proceed in continuous time circulating reactor under hydrogen excess. The presented mathematical model should respect the following conditions:

- Reaction mixture is perfectly mixed by circulation.

- The volume of reaction mixture is constant.

- All technological parameters in reactor are constant.

- Heat transfer on the both sides of wall is ideal.

The hydrogenation mechanism of benzene is supposed to be a first-order reaction:

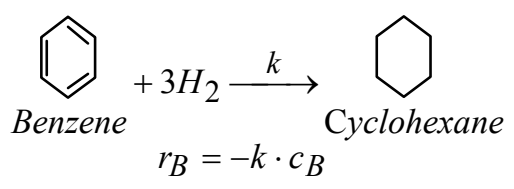

where $k$ is a constant of proportionality known as the rate constant and $r_{B}$ is the rate of the reaction. There is not the rate at which a particular component reacts. Components benzene and hydrogen are consumed by the reaction and thus are "formed" at a negative rate. The material balance for the component benzene satisfies the 
following differential equation (for constant volume $V$ of reactor):

$$
q_{v} \cdot c_{B v}=q \cdot c_{B}+V \cdot k \cdot c_{B}+V \frac{d c_{B}}{d t}
$$

where $q_{v}$ and $q$ are input and output flow and $c_{B v}$ and $c_{B}$ are input and output concentration of component benzene.

The temperature balance in the reactor satisfies the differential equation:

$$
\begin{aligned}
& q_{v} . \rho_{v} \cdot c_{p v} \cdot T_{v}+\left(-\Delta H_{R}\right) V \cdot k \cdot c_{B}= \\
& q . \rho . c_{p} \cdot T+F \cdot \alpha\left(T-T_{x}\right)+V . \rho . c_{p} \frac{d T}{d t}
\end{aligned}
$$

where the relation $\left(-\Delta H_{R}\right) V \cdot k \cdot c_{B}$ is the heat generated by the reaction and $F . \alpha\left(T-T_{x}\right)$ represents the heat transfer into surroundings.

The rate constant $k$ for elementary reactions is expressed by Arrhenius equation:

$$
k=k_{0} T^{n} \exp \left(\frac{-E}{R T}\right)
$$

where parameter $n=0$ (or $n=0.5,1$ for the special cases of reactions) depends on used theoretical model. $E$ is activation energy and the fraction $E / R$ is called an activation temperature.

After some mathematical manipulations the equation (2) of the benzene concentration variation takes the form:

$$
\frac{d c_{B}}{d t}=\frac{q_{v}}{V} \cdot c_{B v}-\frac{q}{V} \cdot c_{B}-k_{0} e^{-\frac{E}{R T}} \cdot c_{B}
$$

Similarly, variation of the reaction mixture temperature in the reactor is:

$$
\begin{aligned}
\frac{d T}{d t}= & \frac{q_{v}}{V} T_{v}+\left(-\Delta H_{R}\right) \cdot \frac{k \cdot c_{B}}{\rho \cdot c_{p}}-\frac{q}{V} T \\
& -\frac{F \cdot \alpha}{V \cdot \rho \cdot c_{p}}\left(T-T_{x}\right)
\end{aligned}
$$

The time response of the reaction mixture concentration depends on the input flow of the benzene, the concentration of input stream $c_{B v}$, the volume of reactor filling, the specific heat capacity of reaction mixture $c_{p}$ and the rate constant $k$.

The solution of ordinary differential equation (5) requires an initial condition: $c_{B v}=c_{B 0}$ at $t=0$.

From all mentioned parameters the input flow stream into the reactor $q_{\mathrm{v}}$ and its initial concentration $c_{B v}$ can be changed.

\section{CONTOL DESIGN}

The plant uncertainty can be expressed conveniently in terms of the fractional description. It means that linear transfer functions are no more represented as a ratio of two polynomial but two elements of an another ring. For the purposes of robust control in the sense of this contribution any transfer function $H(s)$ of a linear system can be expressed as a ratio of two elements:

$$
\begin{aligned}
& H(s)=\frac{b(s)}{a(s)}=\frac{B(s)}{A(s)} \\
& A(s)=\frac{a(s)}{m(s)} ; B(s)=\frac{b(s)}{m(s)} \\
& m(s)=(s+m)^{n} ; n=\max \{\operatorname{deg} a ; \operatorname{deg} b\}
\end{aligned}
$$

where $a, b$ are polynomials. Elements $A, B, \ldots$ constitute a sub ring $R_{m}(s)$ of the ring of all Hurwitz stable and proper rational functions $R_{s}(s)$. A class of PID like controllers is generated by first and second order systems and all controlled plants will be approximated by such systems. Systems of the second order will be approximated by the following fractional representation in $R_{m}(s)$ :

$$
\begin{aligned}
& H(s)=\frac{b_{0}}{a_{2} s^{2}+a_{1} s+a_{0}}= \\
& =\frac{\frac{b_{0}}{(s+m)^{2}}}{\frac{a_{2} s^{2}+a_{1} s+a_{0}}{(s+m)^{2}}}=\frac{B(s)}{A(s)}
\end{aligned}
$$

For $m=0$ subring $R_{m}(s)$ expands to the traditional ring $R_{s}(s)$ (see Vidyasagar, 1985). An infinity norm (convenient for uncertainty) in both rings is defined by

$$
\begin{aligned}
& \|H\|=\sup _{\operatorname{Re} s \geq 0}|H(s)|=\sup _{\omega \in E}|H(j \omega)| \\
& \left\|H_{1} H_{2}\right\|=\left\|\begin{array}{l}
H_{1} \\
H_{2}
\end{array}\right\| \sup _{\operatorname{Re} s \geq 0}\left\{\left.H_{1}(s)\right|^{2}+\left|H_{2}(s)\right|^{2}\right\}^{\frac{1}{2}}
\end{aligned}
$$

This norm is the radius of the smallest circle containing the Nyquist plot of the transfer function. Almost all mathematical models differ from physical systems. Let $H(s)=\frac{B(s)}{A(s)}$ be a nominal plant and consider a family of perturbed systems $H^{\prime}(s)=\frac{B^{\prime}(s)}{A^{\prime}(s)}$ where

$$
\begin{aligned}
& \left\|A-A^{\prime}\right\| \leq \varepsilon_{1} \quad\left\|B-B^{\prime}\right\| \leq \varepsilon_{2} \\
& \text { or }\left\|A-A^{\prime} \quad B-B^{\prime}\right\| \leq \varepsilon
\end{aligned}
$$

Control systems depicted in Figure 1. and Figure 2. are considered for design of a robust $\mathrm{FB}$ and FBFW controllers. 


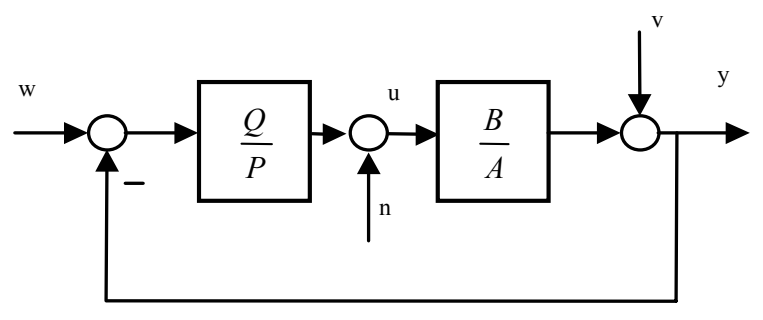

Figure 1. Feedback control system

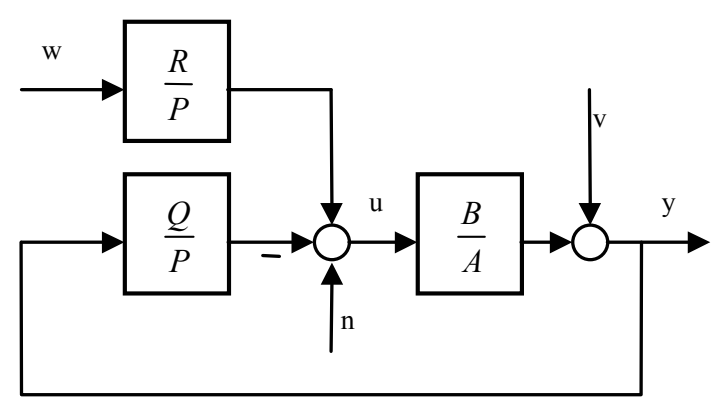

Figure 2. Feedback-feedforward control system.

Transfer functions $w=\frac{G_{w}}{F_{w}}$ and $v=\frac{G_{v}}{F_{v}}$ represent the reference and disturbance signal, respectively. The control design in $R_{m}(S)$ is proposed in (Prokop and Corriou 1997), (Prokop and Dostál 1995). For the given nominal plant $H(s)$ in the form of (7) it consists of the following steps:

Step 1: All stabilizing (feedback) controllers are given by all solutions of the equation:

$$
A P+B Q=1
$$

in the parameter form expressed by the fraction:

$$
\frac{Q}{P}=\frac{Q_{0}-A T}{P_{0}+B T}
$$

where $P_{0}, Q_{0} \in R_{m}(s)$ are particular solutions and $T$ is arbitrary in $R_{m}(s)$.

Step 2: Feedback controllers (if necessary) are given in a similar way by all solutions of

$$
F_{w} S+B R=1
$$

Step 3: Compute $P \in R_{m}(s)$ such that

$F_{w}$ divides $P$ for asymptotic tracking problems

$F_{v}$ divides $P$ for disturbance rejection problems

Step 4: For perturbed plants (10) choose such $P, Q$ in (11), (12) which fulfils the conditions

$$
\begin{aligned}
& \varepsilon_{1}\left\|P_{0}+B T\right\|+\varepsilon_{2}\left\|Q_{0}-A T\right\| \leq 1 \\
& \text { or } \varepsilon\|\| \begin{array}{c}
P_{0}+B T \| \\
Q_{0}-A T \| \leq 1
\end{array}
\end{aligned}
$$

Steps 1 - 3 represent the first and simplest case of robust design. All solutions of Diophantine equations in $R_{m}(s)$ are expressed as functions of the parameter $m>0$. The value of this parameter strongly influences dynamics as well as robustness of the proposed control system. For a deeper insight into robustness the notions of the sensitivity function:

$$
\in=\frac{y}{v}=\frac{1}{1+H C_{b}}=A\left(P_{0}+B T\right)
$$

can be utilized as the second possibility. Similarly, for SISO systems $\epsilon$ is also a function of a scalar parameter $m>0$ and it can be minimized by a simple scalar optimization method. In this way the "most robust" controller for a given nominal plant is obtained. The third case covers situations where perturbed plants are known and the norms in (10) can be evaluated. Then inequalities (15) yield generally nonlinear inequalities for the scalar parameter $m>0$ which can be solved numerically.

\section{SIMULATION EXPERIMENTS}

The continuous-flow circulation reactor for catalytic hydrogenation of benzene with $V=0,5 \mathrm{~m}^{3}$ volume was used for the simulation of the concentration and temperature characteristics. Initial input flow into the reactor was $q_{v}=0.0067 \mathrm{~m}^{3} \mathrm{~s}^{-1}$ with the initial concentration of benzene $c_{B v}=1.9 \mathrm{~kg} / \mathrm{m}^{3}$. Initial rate constant was considered $k=1.616 . \mathrm{e} 14 \mathrm{~s}^{-1}$, density of mass $\rho=985 \mathrm{~kg} \mathrm{~m}^{-3}$, specific heat capacity $c_{p}=4.050$ $\mathrm{J} / \mathrm{kg} . \mathrm{K}$, transfer heat coefficient $E=435.00 \mathrm{~W} / \mathrm{m}^{2} . \mathrm{K}$, surface $F=5.5 \mathrm{~m}^{2}$, activation energy $E=4.8 \mathrm{e} 4 \mathrm{~J} \mathrm{~mol}^{-1}$, initial mass temperature $T_{v}=320 \mathrm{~K}$ and temperature of surrounding $T_{x}=290 \mathrm{~K}$.

\section{Steady-State Analysis Results}

The reactor steady-state characteristics were obtained by solution of equations (4)-(6). The initial conditions were computed by a standard optimization method - iterative procedure.

\section{Dynamic Analysis Results}

For dynamic analysis purposes one input and one output choices were considered. Then were defined input $u$ and output $y$ as deviations from their steady-state values $u(t)=q(t)-q^{s}(t)$ and $y(t)=c_{B}(t)-c_{B}^{s}(t)$.

Graphical interpretation of simulation experiments - the output $y$ time responses to input $u$ step changes are depicted on Figure 3. 


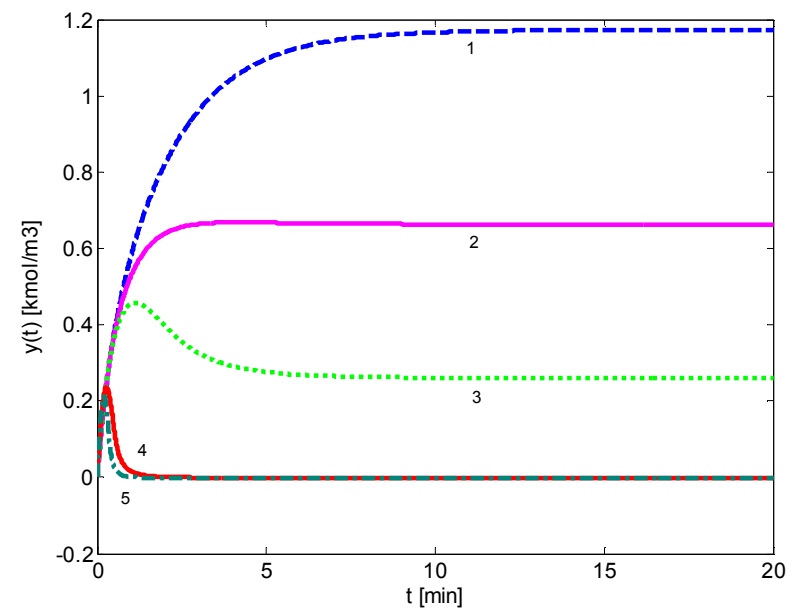

Figure 3: The output $y$ time responses to input $u$ step changes, $\mathrm{u}=-0.08(1),-0.07(2),-0.05(3), 0.05(4), 0.08(5)$

\section{Model approximation}

For control requirement, described continuous time circulating reactor was approximated by the second order system in the form:

$$
H_{1}(s)=\frac{1.9}{71 s^{2}+10 s+0.5} \approx \frac{B(s)}{A(s)}
$$

The approximation was obtained by a four-parameter method adopted from (Astrom and Hagglund 1995) applied to step responses.

For the additional testing of designed robust controllers there was used another nominal system as second order system with unit parameters:

$$
H_{2}(s)=\frac{1}{1 s^{2}+1 s+1} \approx \frac{B(s)}{A(s)}
$$

\section{Control results}

One of the main problems of the catalytic hydrogenation of benzene in continuous-flow circulation reactor is progressive degeneration of reaction surfactant. This is cause that the reaction is slowing down, the rate constant $k$ is decreasing and the concentration of benzene in output mixture is increasing. The aim is to keep the concentration of benzene under the critical value. One of the possibilities how to solve the problem is reduction of input flow $q$ of the benzene and cyclohexane mixture into the reactor.

In spite of the situation, it is desirable to find a robust controller which is "sufficiently acceptable". More precisely, the control goal is to design (in a robust way) a FB and FBFW controllers according to above mentioned methodology for nominal plants and choose such values of $m>0$ which give suitable control responses.

Both FB and FBFW control schemes gave the same optimal value of user defined "tuning knob" $m$. Derivation of controller parameters does not bring any problems.
Simulation 1: Nominal plant: $\mathrm{H}_{1}, m=2$, set point $\mathrm{w}=0.002$, FB controller: $\frac{Q(s)}{P(s)}=\frac{2.87 s^{2}+2.09 s+0.53}{0.01 s^{2}+0.05 s}$.

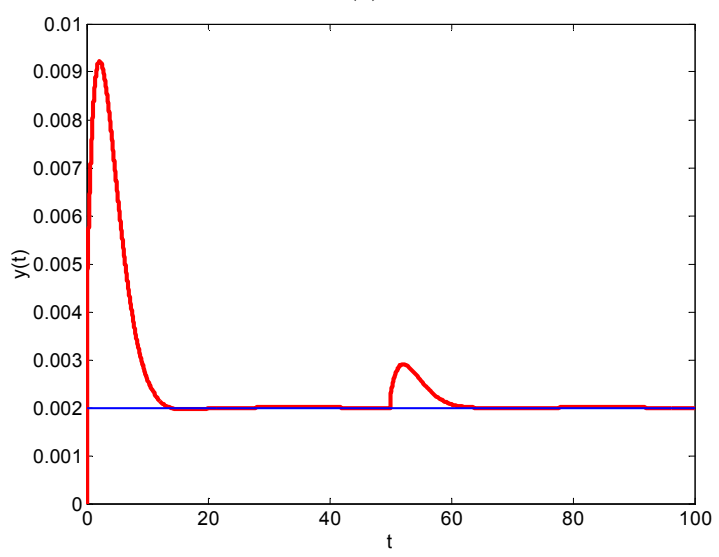

Figure 4. Simulation 1 - output $y$ and reference $w$.

Simulation 2: Nominal plant: $\mathrm{H}_{1}, m=2$, set point $\mathrm{W}=0.002$, FBFW controller:

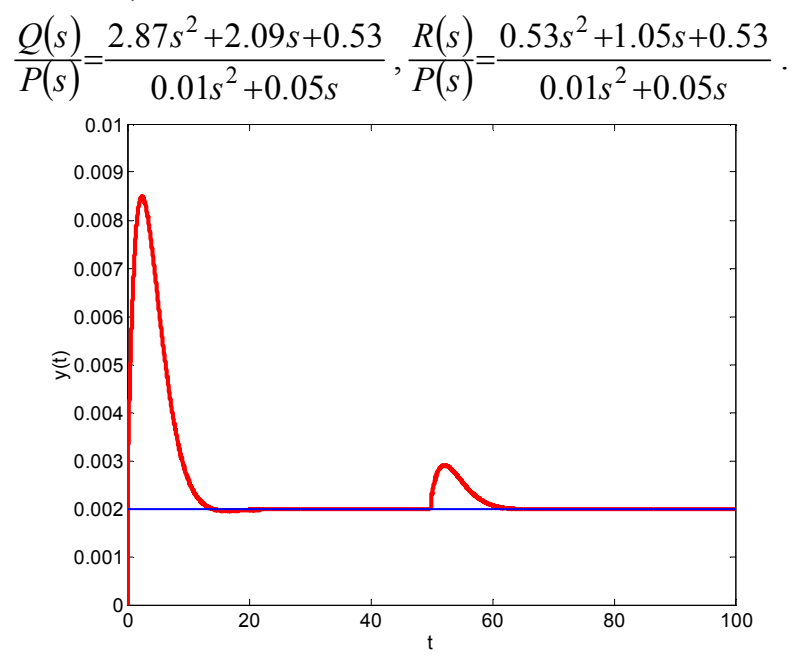

Figure 5. Simulation 2 - output $y$ and reference $w$.

Simulation 3: Nominal plant: $\mathrm{H}_{1}, m=2$, set point $\mathrm{w}=0.002$, FB controller: $\frac{Q(s)}{P(s)}=\frac{12.05 s^{2}+16.81 s+8.42}{0.01 s^{2}+0.11 s}$.

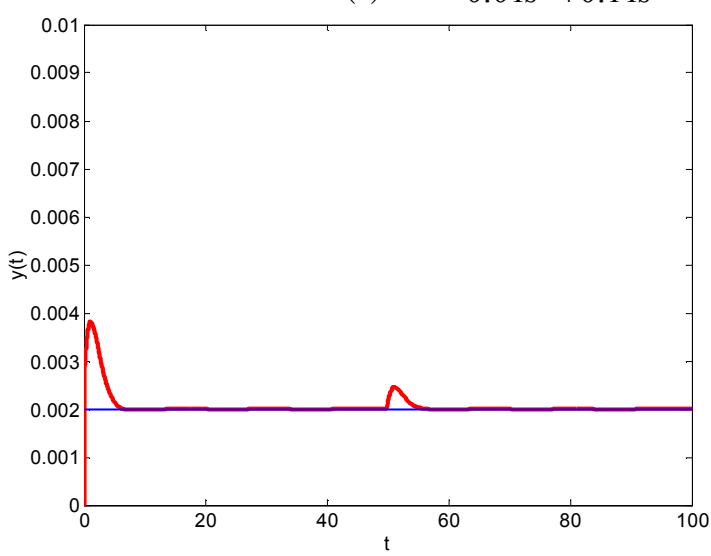

Figure 6. Simulation 3 - output $y$ and reference $w$. 
Simulation 4: Nominal plant: $\mathrm{H}_{1}, \quad m=2$, set point $\mathrm{w}=0.002$, FBFW controller: $\frac{R(s)}{P(s)}=\frac{2.51 s^{2}+8.42 s+8.42}{0.01 s^{2}+0.05 s}$, $\frac{Q(s)}{P(s)}=\frac{12.05 s^{2}+16.81 s+8.42}{0.01 s^{2}+0.11 s}$.

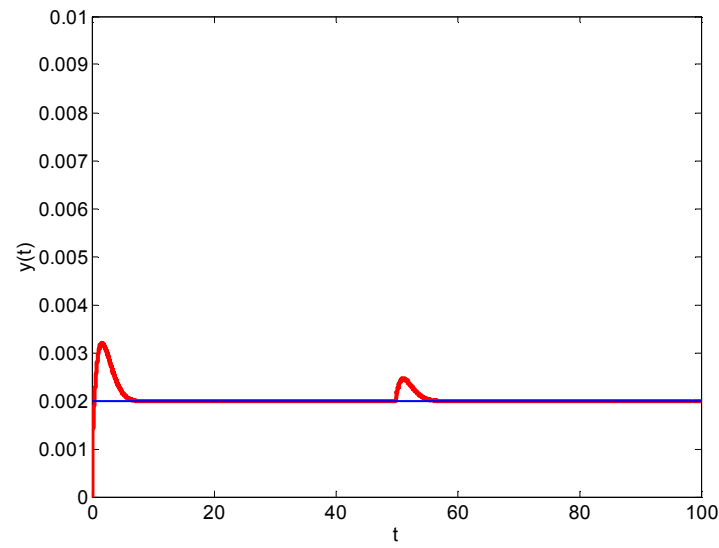

Figure 7. Simulation 4 - output $y$ and reference $w$.

Simulation 5: Nominal plant: $\mathrm{H}_{2}, m=1$, set point $\mathrm{w}=0.002$, FB controller: $\frac{Q(s)}{P(s)}=\frac{2 s^{2}+1 s+1}{1 s^{2}+3 s}$.

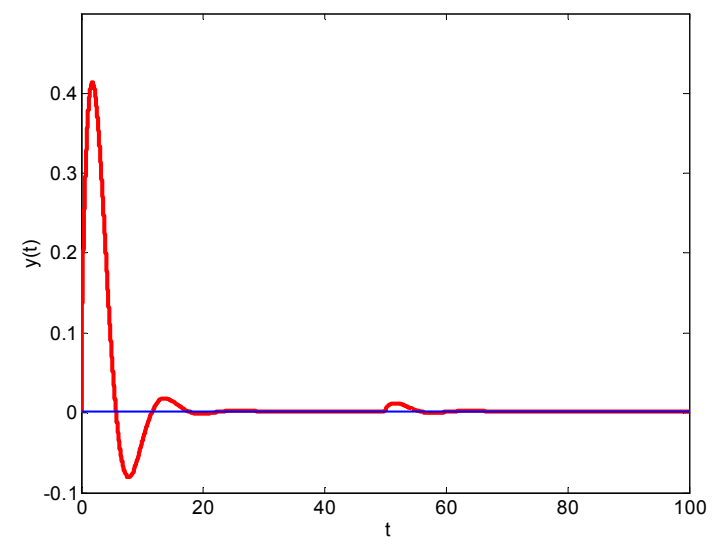

Figure 8. Simulation 5 - output y and reference w.

Simulation 6: Nominal plant: $\mathrm{H}_{2}, m=2$, set point $\mathrm{w}=0.002$, FB controller: $\frac{Q(s)}{P(s)}=\frac{16 s^{2}+25 s+16}{1 s^{2}+7 s}$.

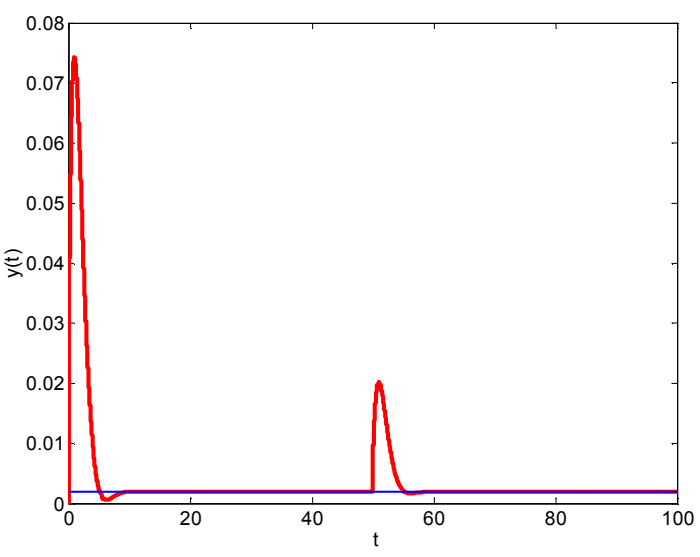

Figure 9. Simulation 6 - output $y$ and reference $w$.
Figure 4 to Figure 9 show the results of Simulation 1 to Simulation 6 of proposed controllers for various nominal plants (11) and (12) and feedback and feedback-feedforward scheme, respectively. Simulation results document that there exist possibility to use robust approach for control of systems with unknown parameters. It is clear that behavior of controlled output value is better when the parameters of nominal plant are closer to real process.

\section{CONCLUSION}

The proposed methodology enables to tune and influence the robustness and control behavior by a single scalar positive parameter. Control laws for first order systems yield a class of PID - like controllers. As we can see on the figures the control results for only feedback and feedback feedforward controllers are very similar in this case. Only the overshooting is slightly smaller in the feedback case. A design method based on the fractional representation was developed for SISO systems generally. All computations and simulation were performed in the MATLAB+SIMULINK environment.

\section{Acknowledgments}

The work has been supported by the Ministry of Education of the Czech Republic in the range of the project No. MSM 7088352102. This support is very gratefully acknowledged.

\section{REFERENCES}

Astrom, K.J., Hagg1und, T. 1995. PID Controllers: Theory, Design and Tuning, 343 p. Instmment Society of America.

Dean, A., J. 1992. Lange's Handbook of Chemistry. 14 edition. McGraw-Hill, INC, New York.

Doyle J.C., Francis B.A., Tannenbaum A.R. 1992. Feedback Control Theory. Maxwell McMillan.

Eaton, A.D., L.S. Clesceri and A.E. Greenberg. 1995. "Standard methods of the examination of water and wastewater". In: $19^{\text {th }} E d n$. APHA, Washington D.C.

Felder, R. M. and Rousseau, R. W. 2000. Elementary Principles of Chemical Processes, 3rd ed., Wiley, New York.

Froment, F. and K. B. Bischotf. 1990. Chemical Reactor Analysis and Design, 2nd ed., Wiley, New York..

Janáčová, D.; Kolomazník, K.; Vašek, V. et al. 1997. "Washing Processes Optimization". In Proceedings of International Union of Leather Technologists and Chemists Societies, pp. 750, Centenary Congress. British Leather Centre. London.

King, M. B. and M. B. Winterbottom. 1998. Reactor Design For Chemical Engineers, Chapman \& Hall, London..

Kolomazník, K.; Janáčová, D. \& Langmaier, F., et. al. 1998. "Enzymatic Digestion of ChromeTanned Solid Waste". In Proceedings of the $1^{\text {st }}$ International Fur Congress. p. 134146. Kastoria, Macedonia Research Center, Greece

Kučera, V. 1993. "Diophantine Equations in Control A Survey", Automatica, 29, No.6, pp. 1361-75.

Nauman, E. B. 2002. Chemical reactor design, optimization, and scaleup. McGRAW-HILL, New York. ISBN: 0-07-137753-0. 
Prokop, R., Corriou, J.P. 1997. "Design and Analysis of Simple Robust Controllers". Int. JournalofControl, Vol. 66, No. 6, pp. 905-921.

Prokop, R., Dostál, P. 1995. "Design of Simple Robust Controllers". In 10th International Conference on PC'95. Tatranské Matliare, pp. 103-108.

Prokopová, Z. 2005. "Analysis and mathematical models of rotary reactors". In 15th International Conference on $P C^{\prime} 05$. Bratislava : STU, pp. 501-504. ISBN 80-2272235-9.

Rangel-Serrano, A., M.V. Maldonado, and K Kösters. 2003. "Characterization of Waste Matherials in Tanneries for Better Ecological Uses". The Journal of the American Leather Chemists Association, Vol. 98, No. 2., pp. 43-48.

Vidyasagar, M. 1985. Control System Synthesis: A Factorization Approach. MIT Press, Cambridge.

\section{AUTHOR BIOGRAPHIES}

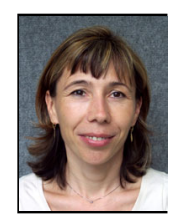

ZDENKA PROKOPOVÁ was born in Rimavská Sobota, Slovak Republic. She graduated from Slovak Technical University in 1988, with a master's degree in automatic control theory. Doctor's degree she has received in technical cybernetics in 1993 from the same university. Since 1995 she is working in Tomas Bata University in Zlin, Faculty of Applied Informatics. She is now working there as an associating professor. Research activities: mathematical modeling, simulation, control of technological systems, programming and application of database systems. Her e-mail address is : prokopova@fai.utb.cz.

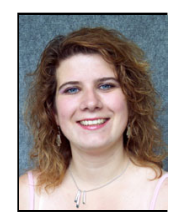

ZUZANA OPLATKOVÁ was born in Zlín, Czech Republic. She graduated from Tomas Bata University in Zlín in 2003, with a master's degree in automatic control theory. Since 2003 she is working in Tomas Bata University in Zlín, Faculty of Applied Informatics as assistant. Research activities: evolution algorithms, symbolic regression, analytic programming, genetic programming. Her e-mail address is : oplatkova@fai.utb.cz. 